\title{
Sociedade do conhecimento, cidades empreendedoras e competivividade local
}

\section{Knowledge society, entrepreneurial cities and local competitiveness}

DOI: $10.54018 /$ sssrv3n1-013

Recebimento dos originais: 14/12/2021

Aceitação para publicação: 18/01/2022

\section{Uranilson Barbosa de Carvalho}

Economista com Mestrado em Economia pela Universidade Federal de Pernambuco

Coordenador Geral Administrativo da Faculdade Frassinetti do Recife - FAFIRE Endereço profissional: Av. Conde da Boa Vista, 921 - Boa Vista - Recife/PE E-mail: uranilsonc@fafire.br

\section{Maria das Graças Soares da Costa}

Doutorado em Educação pela Universidade Federal de Pernambuco - UFPE Instituição: Faculdade Frassinetti do Recife - FAFIRE Endereço: Av. Conde da Boa Vista, 921 - Boa Vista - Recife/PE E-mail: mdasgracas@fafire.br

\section{Moisés Benigno da Silva}

Analista de Sistemas com Mestrado em Ciências da Computação pela Universidade Federal de Pernambuco - UFPE

Procurador Institucional da Faculdade Frassinetti do Recife - FAFIRE.

Endereço: Av. Conde da Boa Vista, 921 - Boa Vista - Recife/PE.

E-mail: moisesb@fafire.br

\section{RESUMO}

O novo paradigma da Sociedade do Conhecimento vem respaldar uma série de inovações peculiares, como a tecnologia da informação, a tecnologia digital e a microeletrônica. Tudo isso impacta nos ditames das organizações com a proliferação de conteúdos como os da computadorização, sistematização e flexibilização, interligação em rede, just in time, inteligência competitiva, entre outros, além do surgimento das novas regras trabalhistas e da desregulamentação estatal, com exigência de uma maior eficiência da gestão pública, visando à integração competitiva no mercado global, com papel dos Governos menos "gerencialistas" e mais direcionada à multiplicação dos novos meios de desenvolvimento econômico. Direcionamos assim para a premissa do "empreendedorismo coletivo", sendo necessária a "busca de uma maior eficiência na gestão urbana, visando a integração competitiva no mercado global" (MOURA, 1997, p. 42). Há uma mudança verificada, principalmente a partir da década de 80, notadamente, na Europa e nos Estados Unidos da participação dos governos locais, com atuação menos intervencionista e mais multiplicadora dos novos meios de desenvolvimento econômico. Neste aspecto, havia uma simetria 
vantajosa entre os países de capitalismo avançado e as cidades empreendedoras. A superação de uma ação pública local, voltada simplesmente à provisão de serviços e regulação do uso e ocupação do solo, para uma perspectiva empreendedora das cidades, conduz à adoção de políticas estratégicas como ações na melhoria da qualidade de vida. Nesse caso, destacam-se os movimentos culturais e a área de entretenimento, os recursos de base e de infraestrutura e o controle e comando de altas finanças. O marketing urbano torna-se outra ferramenta essencial para vender uma imagem positiva da cidade, atraindo para si investimentos nacionais e estrangeiros. Entretanto, Harvey (1996, p. 60) afirma que "Na verdade, a venda da cidade como um espaço para atividades depende muito da criação de um imaginário urbano atraente". No sentido literal da frase, "criação de um imaginário urbano atraente" é estabelecer uma rede de informações eficientes de constantes vínculos institucionais das características que se destacam na cidade, capazes de potencializar os investimentos. O novo perfil de gestão pública deve estar em alinhado com os aspectos básicos do empreendedorismo, nos quais prevalece a ênfase no desenvolvimento econômico, numa perspectiva de integração competitiva; um governo que assume mais um papel de articulador/catalizador de forças; a formação de consensos em torno de projetos estratégicos; a construção de parcerias e redes de ação pública; o desenvolvimento de um expressivo marketing urbano, visando a formação interna e externa da cidade; a utilização de práticas de organização e gerenciamento empresarias que são elementos que caracterizam um movimento que aparece como renovador da gestão pública local, na atualidade. (MOURA, 1997) Em síntese, as variáveis para mensurar os aspectos de atração dos investimentos para as cidades no competitivo mercado global não serão apresentadas espontaneamente, a inserção neste sistema dependerá muito mais da postura de gestão pública das cidades, inserindo-as no novo paradigma da Sociedade do Conhecimento e tornando-as atraentes às iniciativas empreendedoras.

Palavras chave: empreendedorismo, sociedade do conhecimento, desenvolvimento local, gestão pública e competitividade.

\section{ABSTRACT}

The new paradigm of the knowledge society comes back a number of unique innovations, such as information technology, digital technology and microelectronics. All of this impacts us dictates of organizations with the proliferation of content such as computerisation, systematization and flexibility, network interconnection, just in time, competitive intelligence, among others, in addition to the emergence of new labor rules and state deregulation, requiring a greater efficiency of public administration, aimed at integrating competitive in the global market, with role of Governments less "manageable" and more directed to the multiplication of new means of economic development. We direct to the premise of "collective entrepreneurship", requiring the "pursuit of greater efficiency in urban management, aiming at integrating competitive in the global market" (Moura, 1997, p.42). There is a change, especially since the 80 , notably in Europe and the United States of the participation of local governments, with less " manageable" and more multiplier of new means of economic development. In this regard, there was a symmetry advantageous between countries of advanced capitalism and entrepreneurial cities. The overcoming of local public action, 
addressed simply to the provision of services and regulation of the use and occupation of the soil, to an entrepreneurial perspective of cities, leading to the adoption of strategic policies as actions in improving the quality of life. In this case, the cultural movements and the entertainment area, basic resources and infrastructure and the control and command of high finance. Urban marketing becomes another tool essential to sell a positive image of the city, attracting national and foreign investments for you. "In fact, the sale of the city as a space for activities depends largely on the creation of an attractive urban imagery" (Harvey, 1996, p.60). In the literal sense of the phrase, "creating an attractive urban imagery" is to establish an efficient information network of constant institutional links of the features that stand out in the city, able to enhance investments. The new profile of public administration should be in symmetry with the basics of entrepreneurship, in which prevails the emphasis on economic development, with a view to competitive integration; a Government which assumes another role of articulator/catalyst of forces; the consensus-building around strategic projects; building partnerships and networks of public action; the development of a significant urban marketing, aimed at internal and external training of the city; the use of business organization and management practices that are elements that characterize a movement that appears as local public management renewal, at the present time. (Moura, 1997) In summary, the variables to measure aspects of attraction of investments to the cities in the competitive global market will not be presented spontaneously, the insertion in this system will depend on much more of public management of cities, by inserting them into the new paradigm of the knowledge society and making them attractive entrepreneurial initiatives.

Keywords: entrepreneurship, knowledge society, local development, public management and competitiveness.

\section{INTRODUÇÃO}

As sociedades modernas vivenciam um período de intensas mudanças através da inovação e utilização de tecnologias, elementos fundamentais para o alcance de índices superiores de desempenho e competitividade. Essas mudanças acontecem desde tempos imemoriais. Ao longo dos tempos, as organizações humanas passaram por quatro etapas bem definidas: (1) era da agricultura; (2) era do artesanato; (3) era da industrialização e a (4) era da informação (CHIAVENATO, 2003).

As mudanças sofrem influências de fatores externos (política, economia, aspectos sociais, culturais e legais) e internos (políticas gerenciais, métodos e processos de operação, novos produtos e serviços) (PRAHALAD, 2001; HELLER, 1999). Essas mudanças podem ser bem ou mal conduzidas, dependendo 
diretamente da estratégia escolhida e de preceitos envolvidos no processo (WOOD JR., 2004; BEER, 2003; DUCK, 1999; KOTTER, 1997).

O objetivo principal do nosso trabalho é apresentar as características de uma sociedade cujo modelo econômico está centrado nas profundas mudanças e desafios erguidos a partir das inovações ocorridas com a Tecnologia da Informação.

Esse novo paradigma Tecnológico e Econômico exige dos indivíduos e, especialmente, das Cidades, adequação a um novo modelo de gestão menos intervencionista e com foco no empreendedorismo, através de um comportamento indutor do desenvolvimento de pesquisa, incentivo e difusão tecnológica.

Para atingir tal objetivo, o trabalho é dividido em três etapas. A primeira é apresentar os novos ditames da chamada Sociedade do Conhecimento, traz à luz as principais características desse modelo tecnoeconômico. A segunda aborda a temática referente ao Empreendedorismo, apresenta o conceito deste tema e realiza uma ponte entre a necessidade do novo perfil profissional inovador com a Sociedade do Conhecimento.

E, finalmente, na terceira e última etapa, mostra-se a importância da gestão urbana menos intervencionista que assume mais um papel de multiplicadora dos novos meios de desenvolvimento econômico para promover a integração das cidades no competitivo mercado global.

\section{METODOLOGIA}

De acordo com Minayo (1996, p. 22) a metodologia "[...] inclui as concepções teóricas de abordagem e o conjunto de técnicas que possibilitam a apreensão da realidade". Nesse sentido, para a elaboração deste trabalho, seguimos as orientações conforme adaptação das Normas da Associação Brasileira de Normas Técnicas para Trabalhos Acadêmicos (ABNT). A pesquisa realizada foi essencialmente qualitativa, que fica enquadrada no tipo de pesquisa acadêmica e de base teórica, com uso de artigos e livros para permitir a construção de uma sólida fundamentação teórica com o desígnio em esclarecer um problema estudado. 


\section{LANÇANDO UM OLHAR SOBRE A SOCIEDADE DO CONHECIMENTO}

Em um breve passeio pela história, poderíamos fixar-nos na Inglaterra entre a segunda metade do século XVIII; com um olhar mais atento, observaríamos a etapa em que o capital penetra na produção em escala suficiente para justificar a eclosão de um novo sistema: o capitalismo. E, como podemos observar, a Revolução Industrial estimulou a urbanização, fomentando grandes cidades e propiciou a produção de bens em larga escala.

A "estandardização" e a divisão do trabalho deu o suporte necessário ao êxito da lógica capitalista, com a padronização da produção, através da condição de confeccionar o mesmo modelo em série e da especialização da mão de obra em determinadas tarefas, na qual cada trabalhador executava apenas uma parte do trabalho total. Esse modo de produção conferiu um extraordinário ganho de produtividade.

Nesse sentido, a riqueza de um país encontrava-se na produção dos bens, pois o capital estabelecia o lucro do capitalista. Entretanto, retornando aos dias atuais, percebemos claramente a definitiva união entre ciência e tecnologia, estabelecendo uma vertente dinâmica de produção de bens e serviços incorporados a alta tecnologia e com elevado valor agregado. Essas características mudaram substancialmente o nosso século, com impactos inexoráveis nas relações econômicas e sociais, impondo ao homem contemporâneo um grande desafio estabelecido pela chamada Revolução Digital.

Como podemos observar, apresentam-se como setores dinâmicos: o da informática (supercomputadores, microcomputadores, PCs, softwares) cada vez menores e mais potentes; telecomunicações (comunicação ótica, redes de cabos, satélites, equipamentos de telecomunicações, entre outros); semicondutores (circuitos integrados); megaeletrônica (robôs industriais e comandos digitais) e a biotecnologia. Entre as mais novas fronteiras de pesquisas, inclui, entre outros, 0 estudo do DNA; a fusão de células; os novos materiais (como cerâmicas finas, metais amorfos, plásticos para moldar); e as novas fontes enérgicas, entre elas, especialmente a energia eólica e a solar. (ESPINDOLA, 2004). É importante destacar também a nanotecnologia que vem viabilizando inovações que contribuem significativamente para a resolução de diversos problemas, sobretudo na área da saúde, segurança e do meio ambiente. 
Além disso, faz-se mister observar que, o inevitável desenvolvimento do mundo das altas tecnologias produz uma série de efeitos na sociedade. As relações trabalhistas sofrem fortes impactos. As necessidades multifacetadas de decisões requerem um elevado poder de discernimento das equipes de trabalho (PASSOS, 2004).

Desse modo, a capacidade de discernir torna-se central no contexto dos avanços tecnológicos nas comunicações, a informação circula o mundo numa velocidade sem correlação histórica, as decisões tornam-se tão rápidas quanto os satélites e cabos transoceânicos possam possibilitar.

Os conceitos de espaço e tempo sofrem profundos impactos, as distâncias são eliminadas através da virtualidade onde não há limites ${ }^{1}$ nas comunicações entre os demais habitantes dos continentes africanos, asiáticos, europeus, americanos podem acessar simultaneamente assuntos diversos, desde os mais importantes e de alta relevância aos supérfluos.

Entretanto existe um gap entre a informação e o conhecimento. Ter acesso à informação não significará sua consequente utilização em proveito próprio e da sociedade. O conhecimento não pode prescindir da qualidade na formação intelectual. Nesse sentido, a qualificação não se restringe aos recursos humanos das organizações. Transcende o ponto de alcançarmos o conceito mais amplo de cidadania. Ser cidadão representará ter condições básicas de acesso à informação e a subsequente capacidade de transformá-la em conhecimento. É importante ressaltar os dois tipos de conhecimento: o tácito e o explícito, onde se faz necessário o uso de estratégias para sua sistematização e gestão. (TAKEUCHI, 2008).

Podemos, então, ressaltar três aspectos fundamentais: a) a questão da infraestrutura informacional; b) um corpo de técnicos e cientistas para responder às novas demandas; c) um modelo educacional capacitado e comprometido com a formação de empreendedores.

Se no apogeu do regime "fordista", entendia-se, como infraestrutura para alavancar o progresso de uma nação, a construção de autoestradas e aeroportos, sendo o transporte de suma importância para a determinação de um saudável

\footnotetext{
${ }^{1}$ A não ser aquelas impostas pelas condições de pobreza, falta de infraestrutura informacional e má qualificação nas atribuições de usuário.
} 
sistema produtivo, na Sociedade do Conhecimento, imposta pela Tecnologia da Informação, fazem-se necessários como pré-requisitos: estruturar o desenvolvimento em infovias, redes de (tele)comunicação, sistemas e softwares, o que viabiliza os investimentos para a área de comunicação; as interligações em rede; equipamentos eletrônicos e robóticas e os teleserviços (LASTRES $E$ FERRAZ, 2004); além de uma gama de serviços e conteúdos em diversas áreas, tais como: "cultura, lazer, educação e ensino à distância, saúde e telemedicina e consumo geral, entre tantas outras (atuais e potenciais). (ALBAGLI, 2004, p.302).

Entretanto, observa-se um hiato na infraestrutura informacional entre os países desenvolvidos e os em vias de desenvolvimento. Como possível solução, uma atenção especial a um aspecto que será abordado neste artigo, à capacidade de desenvolvimento das Cidades Empreendedoras como forma de geração, capacitação e atração de investimentos. Neste ponto, iremos verificar à inevitável discussão do papel do Estado para possibilitar os pré-requisitos necessários para minimizar a distância e o atraso existentes.

Na nossa concepção, é fundamental, dentro de uma concepção de Estado Moderno, o entendimento do processo ocorrido nos países de economia avançada, onde se propagou um processo de desregulamentação das telecomunicações. Porém, não podemos negar a importância dos governos, mesmo nessas nações, na constituição direta da estrutura informacional, particularmente no que tange à regulamentação e, mesmo, como consumidores dessa infraestrutura (ALBAGLI, 2004).

Destarte, há uma lamentável confusão entre as nações ditas periféricas quanto à questão da participação do Estado nas ordens econômicas e social. Portanto, ao conduzirmos o sentido da importância da participação da gestão pública no processo, estamos, para ser mais precisos, deslocando nossa ênfase para um paradigma de abandono do interesse gerencial, concentrando-nos na perspectiva de "facilitador" do desenvolvimento em pesquisa, incentivo e difusão tecnológica.

Para o adequado funcionamento de uma sociedade lastreada nos moldes da Tecnologia da Informação, faz-se necessário uma formação de equipes de técnicos e cientistas com capacidade de alimentar o desenvolvimento da criação e produção de hardware e software, como também da sua manutenção. Neste 
sentido a universidade, através de projetos de $P \& D^{2}$, tem um papel preponderante, cujo propósito torna-se transpor a inovação (desenvolvida dentro da academia) e coloca-la à disposição da sociedade.

$\mathrm{E}$, finalmente, na perspectiva do usuário, perfaz uma análise mais complexa, pois, em nosso trabalho, consideramos como usuários os indivíduos que estarão preparados e, consequentemente, inseridos na Sociedade do Conhecimento, em condições de acessar a informação e sua utilização na vida pessoal e profissional.

Nesse contexto, apontamos para a necessidade de uma emergente transformação na política educacional dos países ascendentes, congruentes com a desafiadora realidade da conjugação entre ciência e tecnologia. Para tanto, é necessária a formação de pessoas com capacidade de apre(e)ender continuamente, tornando-se cônscias de que, na "Revolução Tecnológica", mais importante não é só ter um diploma, mas ter a capacidade de aprender a aprender.

\section{FORMAÇÃO DE EMPREENDEDORES PARA A SOCIEDADE DO CONHECIMENTO}

A origem da palavra empreendedorismo vem do termo francês entrepreneur, adaptado ao português. Estudo por diversos pensadores e pesquisadores, desde Cantillon (1755), passando por Schumpeter (1934), até os contemporâneos Drucker (1979), Pinchot (1985), Filion (1986), Dolabela (1986), Leite (2000) entre outros, o empreendedorismo revela-se um vasto campo para pesquisa.

Apesar de ser um tema aparentemente novo, o assunto já foi abordado pelo economista austríaco Joseph Alois Schumpeter (1883 - 1950), considerado o precursor da teoria do desenvolvimento capitalista. Schumpeter defendia a lógica dos ciclos econômicos, assegurando que para a recuperação dos períodos de recessão seriam responsáveis, principalmente, as inovações tecnológicas introduzidas por empreendedores. Para ele, sem empresários de visão vanguardista com suas propostas inovadoras, a economia manter-se-ia estática.

\footnotetext{
${ }^{2}$ Pesquisa e Desenvolvimento.
} 
Ao tratar das inovações tecnológicas, Schumpeter afirma que, existem alguns fatores fundamentais, entre eles: (1) a fabricação de um novo bem; (2) a introdução de um novo método de produção; (3) a abertura de um novo mercado; (4) a conquista de uma nova fonte de matérias-primas, nessa realidade, favorecem as "ocasiões de investimentos", variável imprescindível ao crescimento econômico (SCHUMPETER, 1997).

Portanto, para Schumpeter (1996), a inovação é o alicerce do desenvolvimento econômico, pois "o desenvolvimento consiste primeiramente em empregar recursos diferentes de uma maneira diferente, em fazer coisas novas com elas, independentemente de que aqueles recursos cresçam ou não (...). Chamamos "empreendedorismo" à realização de combinações novas (...)" (p. 77, 83).

Para Filion (1991) "um empreendedor é uma pessoa que imagina, desenvolve e realiza visões. Nesta direção Dollabela (2014) afirma que, "a idiossincrasia do empreendedor é perceber oportunidades, transformar sonhos em realidade, considerar que o erro e o fracasso são ocasiões para aprender alguma coisa.

Numa perspectiva mais ampla, o empreendedorismo abrange diversos ramos de atividades, não se restringindo apenas à concepção de um negócio propriamente dito, mas envolvendo um conjunto de atividades em que a exigência básica é a inovação. Nesse sentido pode-se empreender como funcionário em uma empresa de terceiros, o que se denomina de intraempreendedorismo ou mesmo executar atividades de ação benemérita, sem fins lucrativos, estabelecendo o empreendedorismo social.

Em qualquer ramo de atuação, pode-se utilizar a criatividade e o poder da inovação. Tal procedimento proporciona a realização e, possivelmente, o sucesso de qualquer empreendimento, grande ou pequeno, pois, a realização pessoal estimula a constante motivação para a busca de novas maneiras de fazer coisas antigas, a considerar a informação como uma matéria prima a ser transformada em conhecimento que possa agregar valores. Além de aprender sempre, mesmo, ou principalmente, nas adversidades, descobrindo outras possibilidades, graças à experiência, torna-se imune a novas e inesperadas intempéries. 
Desse modo, à luz dos novos tempos, destacamos os traços fundamentais para preservar o empreendedorismo, estimulando e respeitando essa notável peculiaridade do homem para fazer frente aos aspectos inerentes à nova ordem econômica internacional, fundamentada na Tecnologia da Informação e a desregulamentação dos mercados, que impacta, direta e indiretamente, os diversos atores sociais que integram a Sociedade do Conhecimento.

Para essa nova sociedade, o espírito empreendedor é condição sine qua non. E, nesse contexto, as instituições de ensino assumem um papel relevante na difusão da lógica empreendedora e contribuem para indicar os caminhos que conduzem ao processo de codificação das informações. Num sistema educacional sensível aos valores interpessoais, sabe-se que a individualidade, por si, é passível de alcançar êxito dentro do complexo mosaico social.

Estimular a vontade de apre(e)nder continuamente. Este é o lema principal. Não necessitamos de pessoas programadas para multiplicar uma mesma coisa, pois o que queremos são seres que utilizem toda sua energia em criar e recriar, tudo isso em consonância com os valores éticos e de respeito ao meio ambiente.

Pois, se há algo de verdadeiro em nossas vidas, não é a crença fatalista na miséria e na exclusão social, e sim a crescente capacidade inovadora. Arrebentamos a clausura de poucas oportunidades para galgar um mundo de espaços e possibilidades diversificadas. Não é nenhuma utopia nos moldes de alguns eminentes pensadores de séculos passados, como Owen, Saint Simon, Fourier.

Muito pelo contrário, estamos falando em algo bastante pragmático, pedra angular de um projeto educacional condizente com a formação de cidadãos empreendedores, indispensável para o sucesso de qualquer nova empresa ou para se tornar um exímio intraempreendedor. Algo que condicione a busca pela qualidade de vida transcende os aspectos meramente organizacionais para descortinar possíveis perspectivas de inserção no ambiente social e se integrar facilmente nos mais complexos segmentos da sociedade.

\section{COMPETITIVIDADE E CIDADES EMPREENDEDORAS}

Alimentar o progresso, principalmente dos países em vias de desenvolvimento, é promover uma cadeia resistente de ações multiplicadoras que 
fomentem a expansão das cidades, fruto da confluência do ativismo dos movimentos sociais e dos governos, possibilitando o desenvolvimento de estratégias competitivas.

Esse modelo parte da premissa do "empreendedorismo coletivo", sendo necessária a " busca de uma maior eficiência a gestão urbana, visando à integração competitiva no mercado global' (MOURA; 1997, p. 42). Há uma mudança verificada, principalmente a partir da década de 80. Na Europa e nos Estados Unidos houve uma estratégica mudança da participação dos governos locais, com a atuação menos "gerencialista" e mais multiplicadora dos novos meios de desenvolvimento econômico. Nesse aspecto, analisa Moura (1997), havia uma simetria vantajosa entre os países de capitalismo avançado e as cidades empreendedoras.

A superação de uma ação pública local, voltada simplesmente à provisão de serviços e regulação do uso e ocupação do solo, para uma perspectiva empreendedora das cidades, conduz à adoção de políticas estratégicas como ações na melhoria da qualidade de vida. Nesse caso, destacam-se os movimentos culturais e a área de entretenimento; os recursos de base e infraestrutura; e o controle e comando de altas finanças ou processamento de informação. Cita-se, também, o marketing urbano como outra ferramenta essencial, já salientada por Harvey (1996).

Barríos e Abarca (2001) destacam de maneira sucinta os pré-requisitos à absorção dos negócios no mercado global: "para ganhar posições na rede de cidades onde caminham os negócios da economia mundial, já não basta oferecer um grande mercado. É preciso agregar valor e sedução" (p. 25).

Para Moura (1997), o novo perfil de gestão pública deve estar em simetria com os aspectos básicos do empreendedorismo, nos quais prevalece a ênfase no desenvolvimento econômico, numa perspectiva de integração competitiva; um governo que assume mais um papel de articulador/catalisador de forças; a formação de consensos em torno de projetos estratégicos; a construção de parcerias e redes de ação pública; o desenvolvimento de um expressivo marketing urbano, visando a formação interna e externa da cidade; a utilização de práticas de organização e gerenciamento empresarial que são elementos que 
caracterizam um movimento que aparece como renovador da gestão pública local, na atualidade.

A América Economia Intelligence, departamento de estudos da Revista América Economia, utiliza indicadores específicos para estabelecer o ranking das melhores cidades latino americanas para fazer negócios; destaca além dos tradicionais critérios, como poder de compra da população, os inovadores, como PIB per capita ajustado por custo de vida, violência e o marketing estratégico, que mede a imagem da cidade, sendo esse um produto diferenciado para a conquista da vantagem competitiva. Ainda sobre este indicador, que é denominado de Índice de Competitividade Urbana (ICUR), é composto por oito critérios, cada um apresenta um peso, são eles: Marco de Dinamismo Econômico (25\%); Marco Social e Político (15\%); Poder da Marca (15\%); Infraestrutura e Conectividade (10\%); Serviços a Empresas (10\%); Serviços a Executivos (10\%); Capital Humano $(10 \%)$ e Sustentabilidade e Meio Ambiente (5\%) ${ }^{3}$.

Essa abordagem para mensurar o empreendedorismo e o nível de competitividade, exigindo das cidades grande responsabilidade do desenvolvimento econômico local, é antagônico à política do Welfare State (Estado do Bem Estar Social), que vem apresentando esgotamento frente à incapacidade do Estado em manter em expansão constante as políticas sociais. $\mathrm{Na}$ verdade, ainda que empiricamente, o empreendedorismo vem desempenhando papel fundamental na transição do sistema de produção "fordista", fortemente dependente dos fatores nacionais e alicerçado na teoria keynesiana 4 , para formas de acumulação flexíveis, muito mais abertas geograficamente e com maior autonomia de mercado (HARVEY,1996) ${ }^{5}$.

Ainda fazendo referência à aquiescência do modelo "fordista" e a efetiva proteção de um Estado paternalista, Paulani (2004) analisa que a necessidade do Estado interferir no mercado encontrou seu "habitat natural no Estado do Bem

\footnotetext{
${ }^{3}$ Conforme edição de 2012 do Ranking de Competitividade Urbana. Para a leitura completa da pesquisa, acessar o link: http://rankings.americaeconomia.com/2012/las-mejores-ciudades-para-hacer-negocios-enamerica-latinal

${ }^{4} \mathrm{~A}$ Teoria Keynesiana baseia-se nos postulados do economista Jonh M Keynes (1883-1946). Suas principais contribuições foram escritas no livro A Teoria Geral do emprego, do Juro e da Moeda (1936). Defendia a participação do Estado na atividade econômica, como forma de proporcionar o pleno emprego. Para tanto, propunha, principalmente, uma política fiscal expansionista através da elevação dos gastos públicos.

${ }^{5}$ David Harvey (1996) utiliza a nomenclatura empresariamento urbano, que empregamos no sentido de empreendedorismo.
} 
Estar Social, no controle keynesiano da demanda efetiva e na regulamentação fordista, e o capitalismo deslanchou tranquilo por três décadas, crescendo de modo sustentado em todo esse período, já conhecido na literatura como "os anos de ouro" ( p. 119).

Obviamente que as novas variáveis para mensurar os aspectos de atração dos investimentos para as cidades no competitivo mercado global não serão apresentadas espontaneamente. A inserção nesse sistema dependerá muito mais de um modelo educacional que coadune com os novos paradigmas impostos ao cidadão do século XXI.

A competitividade acirrada estabelecida pelo "globalismo", a flexibilização da mão de obra, os avanços da conjugação da ciência e tecnologia e a minimização do Estado intervencionista impactam sobremaneira nas relações sociais, forjando o que denominamos de Sociedade do Conhecimento.

\section{CONCLUSÃO}

O traço fundamental no desenvolvimento no novo paradigma tecnoecnômico da Tecnologia da Informação se espalha por diversificados e complexos processos de conhecimentos, dando origem à chamada Sociedade do Conhecimento. A microeletrônica, as infovias, as redes de (tele)comunicação, a emergência de qualificação para a inteligência competitiva, entre outras, impõem aos atores sociais a crescente valorização da geração de novos conhecimentos, a flexibilização e maior capacidade de controle nos processos de produção, reduzindo ao máximo os erros; além da necessidade do perfil empreendedor dos agentes econômicos e dos gestores públicos.

Esse último item, em especial, observou-se um hiato na chamada infraestrutura informacional entre países desenvolvidos e os em vias de desenvolvimento. Nas regiões periféricas ainda prevalece o papel tradicional do poder público na provisão de serviços e na burocracia da regulação do uso e ocupação do solo. Como alternativa de solução, para reduzir esse gap, foi sugerido uma atenção especial para o estímulo das diretrizes de Cidades Empreendedoras e gestores públicos sensibilizados com essa nova dinâmica.

Sendo assim, ocorreu a proposição de uma mudança do perfil da gestão pública das Cidades, redirecionando o papel do gestor público do interesse 
"gerencial" para uma perspectiva de "articulador" e "catalizador". Os governos locais devem assumir uma postura que permita a multiplicação dos novos meios de desenvolvimento econômico oriundos, principalmente, do incentivo à capacidade de inovação e atração de investimentos privados nacionais e internacionais. 


\section{REFERÊNCIAS}

ALBAGLI, Sarita. Novos espaços de regulação na era da informação. In: Helena Lastres e Sarita Albagli. Informação e globalização na era do conhecimento. Rio de Janeiro: Campus, 2004.

BEER, Mike (org). Gerenciando mudança e transição. Rio de Janeiro: Record, 2003.

BERRÍOS, Rodrigo e ABARCA, Felipe. Ranking de cidades. Revista América Econômica Dow Jones, n.209, maio de 2001, p. 24,30.

CASSIOLATO, J. E. A economia do conhecimento e as novas políticas industriais e tecnológicas. In: Helena Lastres e Sarita Albagli. Informação e globalização na era do conhecimento. Rio de Janeiro: Campus, 2004.

CHIAVENATO, Idalberto. Os novos paradigmas: como as mudanças estão mexendo com as empresas. 4 ed. São Paulo: Atlas, 2003.

COCCO, Giusepe. A nova qualidade do trabalho na era da informação. Helena Lastres e Sarita Albagli. Informação e globalização na era do conhecimento. Rio de Janeiro: Campus, 2004.

DOBB, Maurice. A evolução do capitalismo. Rio de Janeiro: Guanabara, 1963.

DOLABELA, Fernando. O segredo de Luísa. São Paulo: Cultura, 2012.

DUCK, Jeanie D. Gerenciando a mudança: a arte do equilíbrio. In: HARVARD, Business Review: Mudança. Rio de Janeiro: Campus, 1999.

ESPINDOLA, Haruf Salmen. Ciência, capitalismo e globalização. São Paulo: FTD, 1999.

FILION, L. Les entrepreneurs parlent. Les Éditions de l'Entrepreneur. Montreal, 1990.

HARVEY, David. Do gerenciamento ao empresariamento: a transformação da administração urbana no capitalismo tardio. Espaço \& Debate, n.39, 1996.

HELLER, Robert. Como gerenciar mudanças. São Paulo: Publifolha, 1999.

KOTTER, John P. Oito erros fatais. In: JULIO, Carlos A; NETO, José S. (orgs). Inovação e mudança. São Paulo: Publifolha, 2001.

KOTTER, John P. Liderando a mudança: por que fracassam as tentativas de transformação. In: HARVARD, Business Review: Mudança. Rio de Janeiro: Campus, 1999.

KOTTER, John P. Liderando a mudança. 17 ed. Rio de Janeiro: Elsevier, 1997. 
LASTRES, H. Maria e FERRAZ, J. C. Economia da informação do conhecimento e do aprendizado. In: Helena Lastres e Sarita Albagli. Informação e globalização na era do conhecimento. Rio de Janeiro: Campus, 2004.

LEITE, Emanuel. O fenômeno do empreendedorismo: criando riquezas. Recife: Ed. Saraiva, 2014.

LEMOS, Cristina. Inovação na era do conhecimento. In: Helena Lastres e Sarita Albagli. Informação e globalização na era do conhecimento. Rio de Janeiro: Campus, 2004.

MOURA, Maria S.S. Cidade empreendedoras, cidades democráticas e de redes públicas: tendências à renovação na gestão local. Salvador: Núcleo de Pós-graduação em Administração Pública da UFBA, 1997. (tese de doutorado).

PAULANI, Leda. Neoliberalismo e individualismo. Economia e Sociedade, Campinas, n.13, p.115,128,dez.1999

PASSOS, Kruger. Novos modelos de gestão e as informações. In: Lastres e Ferraz: Informação e globalização na era do conhecimento. Rio de Janeiro: Campus, 2004.

PRAHALAD, C.K. Reexame de competências: como auto-analisar-se para mudar. In: JULIO, Carlos A; NETO, José S. (orgs). Inovação e mudança. São Paulo: Publifolha, 2001.

PINCHOT, G. Intrapreneuring. São Paulo: Harbra, 1999.

SCHUMPETER, Joseph A. Uma investigação sobre lucros, capital, crédito, juro e o ciclo econômico. Coleção Os Economistas. São Paulo: Ática,1996.

TAKEUCHI, Hirokata. Gestão do Conhecimento. Porto Alegre: Bookman, 2008.

WOOD JR, Thomaz. Mudança organizacional: uma introdução ao tema. In: WOOD JR, Thomaz (org). Mudança organizacional. 4 ed. São Paulo: Atlas, 2004. 